\title{
Article
}

\section{Assessing Transformations of Algal Organic Matter in the Long-Term: Impacts of Humification-Like Processes}

\author{
Maud Leloup *, Virginie Pallier, Rudy Nicolau and Geneviève Feuillade-Cathalifaud * \\ EA 4330 Groupement de Recherche Eau, Sol, Environnement (GRESE), \\ Ecole Nationale Supérieure d'Ingénieurs de Limoges (ENSIL), University of Limoges, \\ Parc d'ESTER Technopôle, 16 rue Atlantis, Limoges Cedex F-87068, France; \\ E-Mails: virginie.pallier@ensil.unilim.fr (V.P.); rudy.nicolau@ensil.unilim.fr (R.N.) \\ * Authors to whom correspondence should be addressed; \\ E-Mails: maud.leloup@ensil.unilim.fr (M.L.); feuillade@ensil.unilim.fr (G.-F.C.); \\ Tel.: +33-5-5542-3695 (G.-F.C.); Fax: +33-5-5542-3680 (G.-F.C.).
}

Academic Editors: Christopher Q. Lan and Yanqun Li

Received: 29 May 2015 / Accepted: 27 July 2015 / Published: 5 August 2015

\begin{abstract}
Algae and cyanobacteria are important contributors to the natural organic matter (NOM) of eutrophic water resources. The objective of this work is to increase knowledge on the modifications of algal organic matter (AOM) properties in the long term to anticipate blooms footprint in such aquatic environments. The production of AOM from an alga (Euglena gracilis) and a cyanobacteria (Microcystis aeruginosa) was followed up and characterized during the stationary phase and after one year and four months of cultivation, in batch experiments. Specific UV absorbance (SUVA) index, organic matter fractionation according to hydrophobicity and apparent molecular weight were combined to assess the evolution of AOM. A comparison between humic substances (HS) mainly derived from allochthonous origins and AOM characteristics was performed to hypothesize impacts of AOM transformation processes on the water quality of eutrophic water resources. Each AOM fraction underwent a specific evolution pattern, depending on its composition. Impacts of humification-like processes were predominant over release of biopolymers due to cells decay and led to an increase in the hydrophobic compounds part and molecular weights over time. However, the hydrophilic fraction remained the major fraction whatever the growth stage. Organic compounds generated by maturation of these precursors corresponded to large and aliphatic structures.
\end{abstract}


Keywords: algae; cyanobacteria; transformation processes; organic matter; size fractionation; XAD fractionation

\section{Introduction}

Natural organic matter (NOM) is ubiquitous and its molecular structure is extremely complex. In aquatic environments, NOM is mainly derived from soils, terrestrial plants, aquatic organisms and human activities and its structure evolves continuously due to humification processes.

Humification results from various processes of degradation of organic material and rearrangement of the original products, involving biotic and abiotic reactions. These processes slowly lead to the formation of compounds refractory to biodegradation: the humic substances (HS). HS are composed of humins, humic acids (HA) and fulvic acids (FA), which are experimentally defined by $\mathrm{pH}$ conditions: humins are not soluble, HA are precipitated at $\mathrm{pH} 2$ and FA are soluble whatever the $\mathrm{pH}$ [1]. HS have neither a constant composition nor a clearly identified structure [2]. It is now well stated that humification processes are very complex and several reaction pathways associated to NOM structural models were developed to explain HS genesis. Two main types of models were proposed: polymer models and molecular aggregates models.

HS genesis pathways by polymerization were described by Stevenson [3]. In the polymers models, NOM molecules are large polymers with a chemical structure different from their precursors linked with covalent bonds [4]. Polymer models include theories of lignin, polyphenols, tannins, abiotic condensation of sugars and amino-acids (Maillard type reaction) and plant derived humic substances [3,5-7].

In the aggregates models, NOM is composed of supramolecular aggregates of plant degradation products linked with non-covalent bonds (Van der Waals forces, $\pi-\pi$ interactions, hydrophobic interactions and hydrogen bonds) [8,9]. Supramolecular aggregates are formed with individual components of low molecular weights — 1 to $1.5 \mathrm{kDa}$ —according to Piccolo, and Sutton and Sposito [8,9]. Evidence makes this theory currently the more adequate, with the relatively low molecular weights structures observed for HA (mainly in the range of 0.5 and $30 \mathrm{kDa}$ according to several studies) [10-12].

Humification tends to increase complexity, aromatic carbon content [7,13] and apparent molecular weight of organic compounds [14]. An interesting approach to study these processes consists in fractionating organic matter according to physical (molecular weight fractionation) or chemical properties (fractionation according to the hydrophobic character by using polymeric XAD resins). The obtained fractions are linked to environmental processes and origin of the organic compounds. Organic material from allochthonous sources, such as plants decay from soil run off is mainly hydrophobic with high molecular weight; autochthonous contribution (phytoplankton and bacteria) is composed of more hydrophilic organic molecules of low molecular weight $[15,16]$. Organic matter produced by microalgae and cyanobacteria, thus, contains $57 \%$ to $71 \%$ of hydrophilic compounds according to recent works, depending on the growth phase and the species [17-21].

Humification processes and NOM structures were extensively studied in soils and in a lower extent in aquatic environments. Indeed, the previously described models were designed for NOM derived from soils, where plant contribution is predominant compared to microbial biomass $(<5 \%$ of total carbon of 
soils according to Kassim et al. [22]). The chemical composition of organic matter derived from micro-organisms, which is different from that of plants, was thus not really taken into account. However, microbial activity can be a major component of NOM in natural waters and especially in the eutrophic ones, in which contribution of algal blooms cannot be neglected. Evolution of NOM in eutrophic waters is not well understood, although NOM tends to accumulate in these environments, which is a serious problem for drinking water production.

The objective of this work was to investigate how algal organic matter (AOM) evolves under specific bio-physico-chemical conditions during and after senescence of algae (Euglena gracilis) and cyanobacteria (Microcystis aeruginosa), in batch experiments. Specific UV absorbance (SUVA) index, as well as a combination of organic matter fractionations according to hydrophobicity and apparent molecular weight, were used to assess the evolution of the AOM characteristics from the freshly produced stage (stationary phase) to the degraded stage (advanced decline phase, after one year and four months of cultivation). A comparison with HS properties from soil and surface water resource allowed building hypotheses about AOM transformation pathways in the long term, and its possible consequences for the quality of eutrophic water resources.

\section{Results and Discussion}

\subsection{Evolution of the Hydrophobic and Aromatic Characteristics}

Table 1 shows the evolution of the hydrophobic and aromatic properties of AOM fractions and makes a comparison with NOM fractions.

Table 1. Comparison of aromatic (SUVA) and hydrophobic properties (organic matter fractions content relative to dissolved organic carbon (DOC)) of algal organic matter (AOM) at various growth stages with natural organic matter (NOM).

\begin{tabular}{|c|c|c|c|c|c|c|c|}
\hline \multicolumn{2}{|c|}{ Growth Phase } & \multicolumn{2}{|c|}{ Stationary Phase $^{1}$} & \multicolumn{2}{|c|}{ Decline Phase $^{1}$} & \multicolumn{2}{|c|}{ Advanced Decline Phase } \\
\hline Origin & Fractions & $\%$ of DOC & SUVA ${ }^{2}$ & $\%$ of DOC & SUVA ${ }^{2}$ & $\%$ of DOC & SUVA ${ }^{2}$ \\
\hline \multirow{4}{*}{ Euglena gracilis } & Total & - & $13.9 \pm 0.1$ & - & $11.2 \pm 0.1$ & - & $12.1 \pm 0.1$ \\
\hline & $\mathrm{HPO}^{3}$ & 18 & $19.5 \pm 1.6$ & 24 & $26.4 \pm 3.9$ & 32 & $33.1 \pm 0.9$ \\
\hline & $\mathrm{TPH}^{4}$ & 13 & $17.1 \pm 1.4$ & 15 & $13.5 \pm 1.4$ & 20 & $19.8 \pm 1.1$ \\
\hline & $\mathrm{HPI}^{5}$ & 69 & $8.4 \pm 0.6$ & 61 & $6.9 \pm 0.1$ & 48 & $9.9 \pm 0.1$ \\
\hline \multirow{4}{*}{ Microcystis aeruginosa } & Total & - & $10.7 \pm 1.3$ & - & $10.4 \pm 0.8$ & - & $10.4 \pm 0.1$ \\
\hline & $\mathrm{HPO}^{3}$ & 20 & $12.0 \pm 0.4$ & 24 & $19.0 \pm 2.7$ & 24 & $20.8 \pm 0.4$ \\
\hline & $\mathrm{TPH}^{4}$ & 19 & $7.3 \pm 0.6$ & 29 & $4.0 \pm 1.0$ & 28 & $15.3 \pm 0.3$ \\
\hline & $\mathrm{HPI}^{5}$ & 61 & $11.9 \pm 0.5$ & 47 & $11.6 \pm 0.4$ & 48 & $9.2 \pm 0.8$ \\
\hline Origin & Fractions & \multicolumn{3}{|c|}{$\%$ of DOC } & \multicolumn{3}{|c|}{ SUVA $^{2}$} \\
\hline \multirow{4}{*}{ Pigeard pond } & Total & \multicolumn{3}{|c|}{-} & \multicolumn{3}{|c|}{$36.5 \pm 0.3$} \\
\hline & $\mathrm{HPO}^{3}$ & \multicolumn{3}{|c|}{43} & \multicolumn{3}{|c|}{$52.8 \pm 0.8$} \\
\hline & $\mathrm{TPH}^{4}$ & \multicolumn{3}{|c|}{21} & \multicolumn{3}{|c|}{$27.2 \pm 0.9$} \\
\hline & $\mathrm{HPI}^{5}$ & \multicolumn{3}{|c|}{36} & \multicolumn{3}{|c|}{$14.1 \pm 0.1$} \\
\hline \multirow{2}{*}{ Suwannee River } & HA & \multicolumn{3}{|c|}{-} & \multicolumn{3}{|c|}{$67.9 \pm 0.5$} \\
\hline & FA & \multicolumn{3}{|c|}{-} & \multicolumn{3}{|c|}{$47.4 \pm 0.5$} \\
\hline Peat & HA & \multicolumn{3}{|c|}{-} & \multicolumn{3}{|c|}{$101.0 \pm 0.5$} \\
\hline
\end{tabular}

${ }^{1}$ data from Leloup et al. [21]; ${ }^{2}$ Specific UV absorbance (SUVA) in $\mathrm{L} \cdot \mathrm{cm}^{-1} \cdot \mathrm{gC}^{-1} ;{ }^{3} \mathrm{HPO}$ : Hydrophobic fraction;

${ }^{4}$ TPH: Transphilic fraction; and ${ }^{5}$ HPI: Hydrophilic fraction. 
Several authors already studied the evolution of AOM characteristics between the exponential and stationary growth phases. During this period AOM mainly derives from extracellular organic matter (EOM) release due to photosynthetic activity of living cells. Only little evolution was reported and no general conclusion can be drawn as regards HPO or HPI content increase according to the works by Henderson et al., Leloup et al., and Pivokonsky et al. [18,21,23].

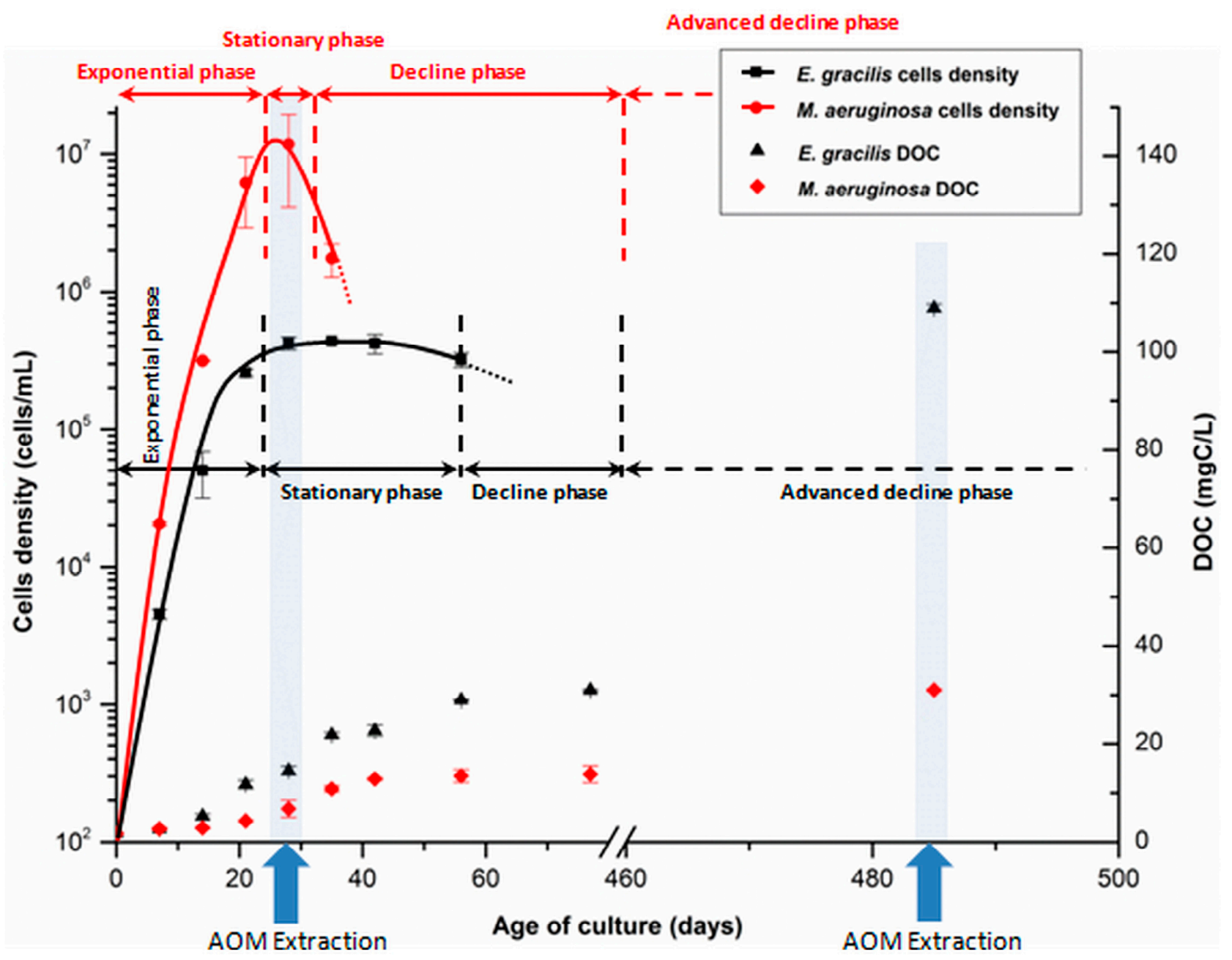

Figure 1. Growth curves and extraction time points of E. gracilis and M. aeruginosa. Cells densities were determined by flow cytometry in a previous study [21].

Highest intracellular organic matter (IOM) release rate is expected to occur between the stationary and decline phases because cells tend to massively die during the blooms collapse. This was especially the case for $M$. aeruginosa (Figure 1). Recent studies compared the hydrophobic characteristics of IOM and EOM $[23,24]$. They demonstrated that IOM is more hydrophilic than EOM $(69 \%-74 \%$ for EOM vs. 87\%-90\% for IOM). A slight increase in the Hydrophilic fraction (HPI) part (as well as the corresponding hydrophobic fraction (HPO) percentage decrease) would thus be expected from cells decay. However, contrary to what was expected, a significant increase in the HPO and transphilic fraction (TPH) parts was observed while the HPI percentage decreased for both species ( $-8 \%$ to $-14 \%)$. This evolution continued until the end of the experiment, after more than a year of cultivation but stage of HA production was not reached $(<3 \%$ of DOC). Several processes could explain these unexpected 
modifications. After the cells death, two additional processes - photo-induced reactions (including dissolution of cells debris) and leaching of particulate organic matter-could contribute to the HPO and TPH increase, as well as transformation of organic compounds (especially the HPI fraction, which is known to be the most labile [25] by microbial activity. It cannot be neglected anymore when compared to exponential and stationary growth phases, during which biological activity form phytoplankton was predominant. Impacts of these processes thus overcame the expected HPI increase from IOM release by cells decay. These processes were then predominant and their consequences on AOM properties - increase in HPO and TPH parts - were consistent with the humification theories.

Some differences can be observed between the two species. Much more evolution of the organic matter properties (aromaticity and hydrophobicity) was observed during the first four months of cultivation than during the following year in the case of M. aeruginosa, compared to E. gracilis. An equilibrium state (according to DOC content) was reached after four months (decline phase) for the cyanobacteria, when the same state of transformation was only achieved during the advanced decline phase for the alga (after more than 12 months). The faster evolution of M. aeruginosa's AOM was probably due to a shorter stationary phase (only seven days long for the cyanobacteria $v s .34$ days for the alga, Figure 1), which allowed degradation and transformation processes from biotic and abiotic factors to occur earlier. E. gracilis population declined slowly, likely because of mixotrophy.

Despite the impacts of transformation processes, AOM remained mainly hydrophilic (48\% of DOC for both species) a long time after senescence, contrary to NOM from natural waters (36\% of DOC for Pigeard pond). Humification-like processes affecting AOM may be different from those occurring in soils (probably because the characteristics of precursors are different and the resulting humic-like substances characteristics may also be different) and/or may require a long time to make AOM characteristics tend to the level of organic matter from allochthonous origin. However, one limitation of this study is that it does not reflect seasonal variations of light intensity and temperature occurring in natural systems over the year, so the impact of transformation processes on the AOM characteristics is probably underestimated.

Whatever the growth phase, SUVA indexes of AOM were lower than those of NOM from allochthonous origin (Table 1), which is consistent with results from Weishaar et al. [26] and correlates with its high HPI content. Leloup et al. [21] already discussed the evolution of AOM SUVA between the stationary and decline phases and compared SUVA values between E. gracilis and M. aeruginosa. From the stationary phase to the advanced decline phase, SUVA index of HPO from both species increased. SUVA of TPH and in a lesser extent of HPI decreased between the stationary and decline phases and increased between the decline and advanced decline phases, except for HPI of M. aeruginosa, which did not evolve so much. Transformation processes affecting HPO seem to be different from the TPH and HPI fractions, probably because the latter are known to be more labile and subject to biodegradation than HPO [25]. The HPO fraction seemed to undergo a slow one-step process, which started immediately after the stationary phase, while the HPI and TPH fractions were affected by a two-step process. Thus, in a first time, both fractions may be degraded by bacterial activity into less aromatic compounds between the stationary and decline phases. In a second step, they may be condensed and reassembled into more complex and aromatic structures. 

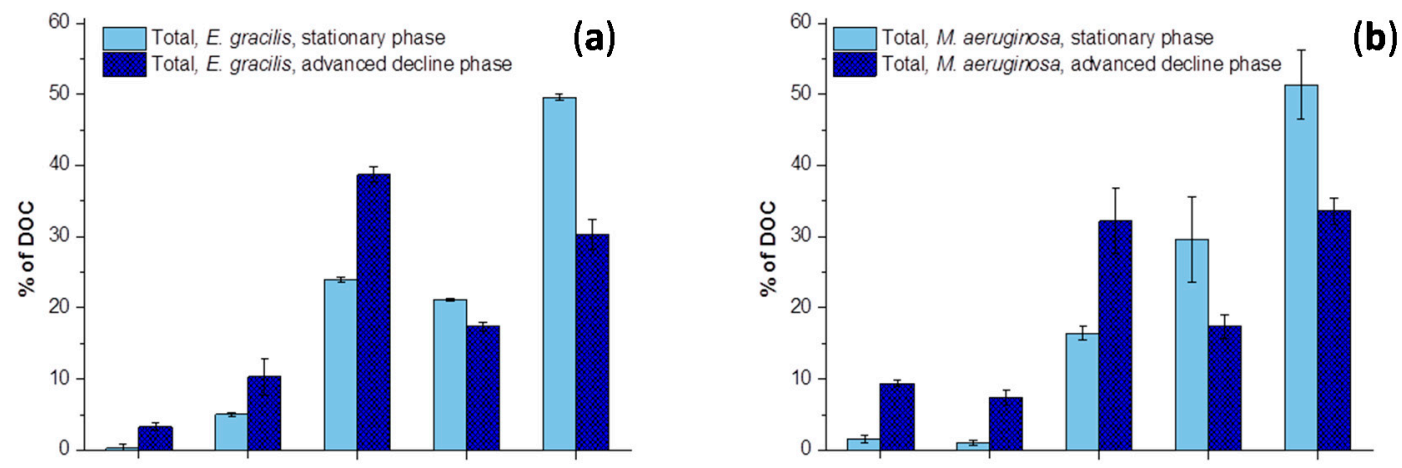

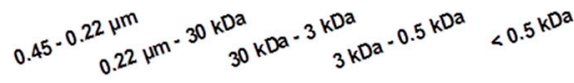

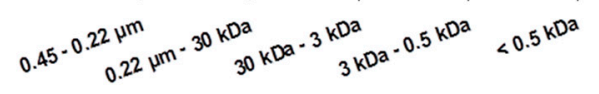
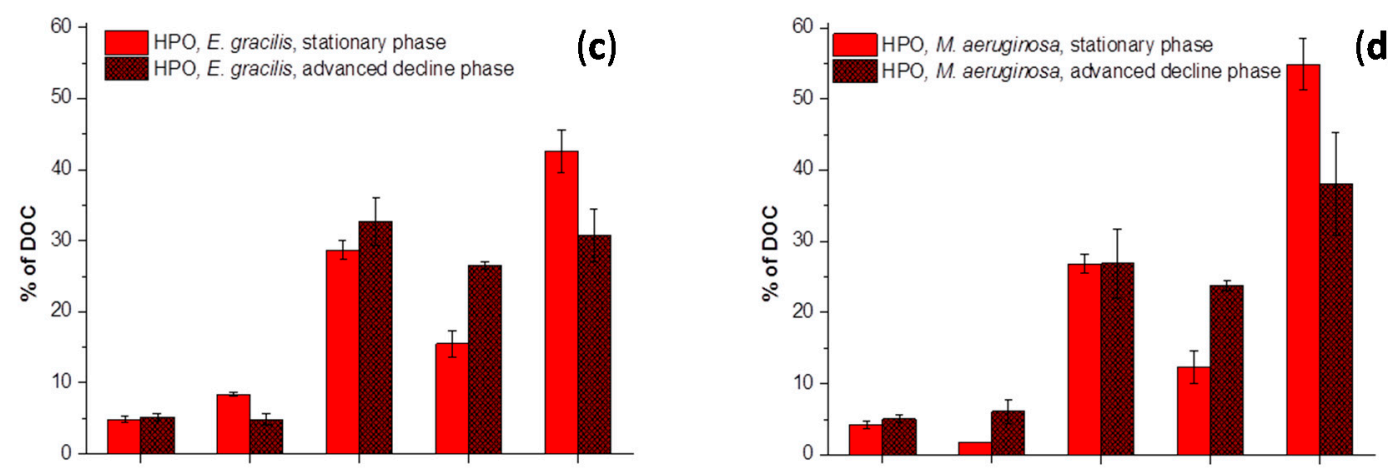



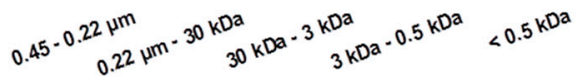
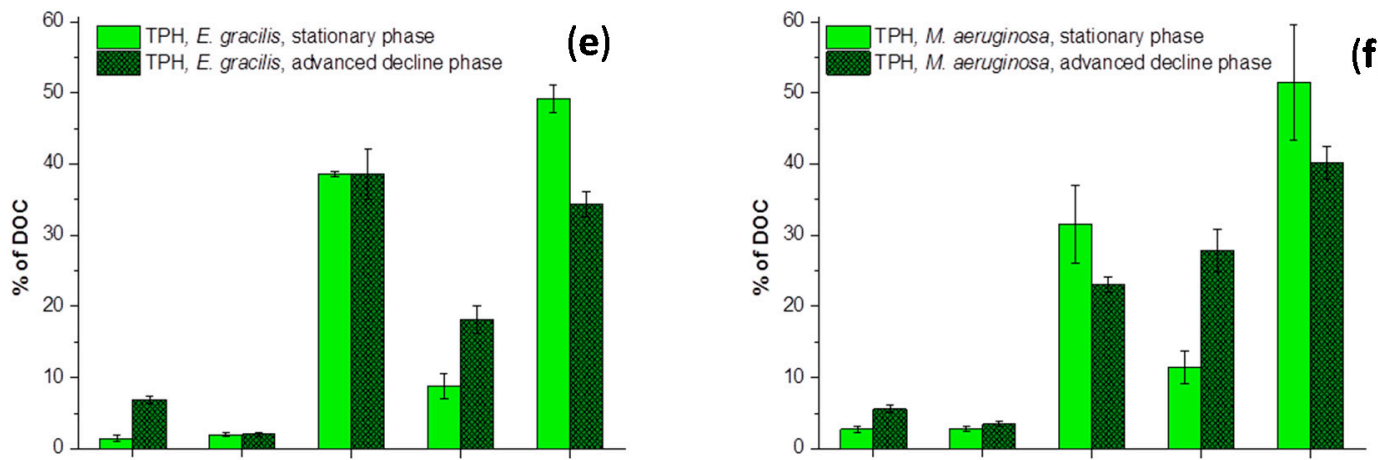

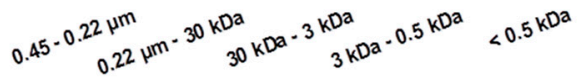

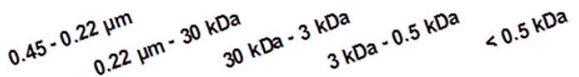
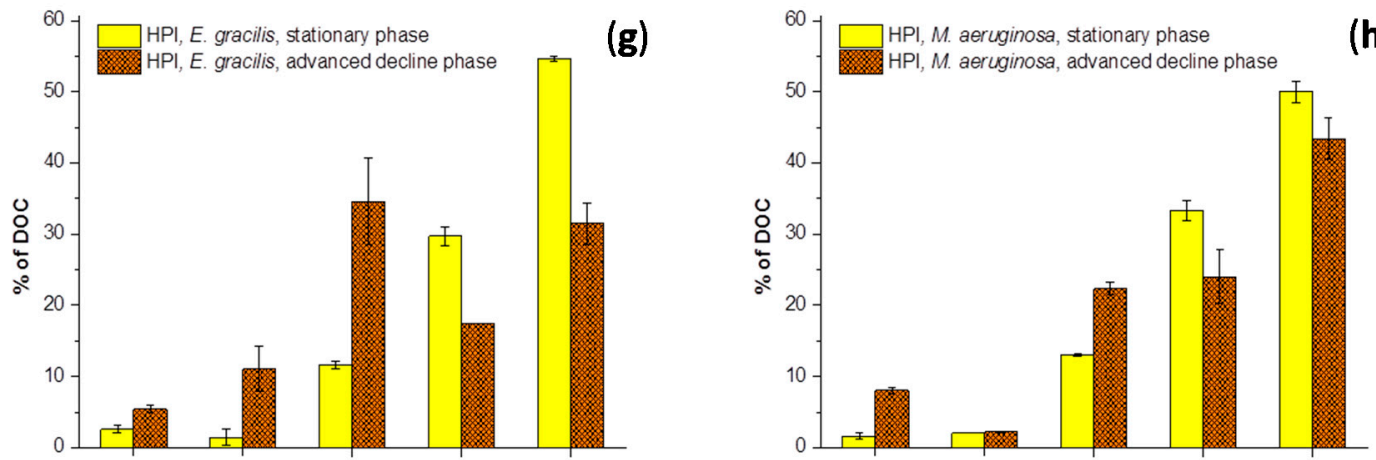

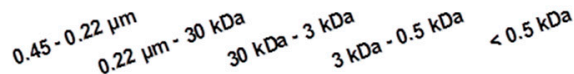

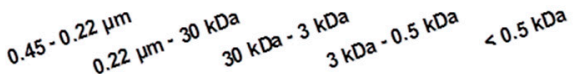

Figure 2. Comparison of size fractionation of dissolved organic matter: Evolution between the stationary and advanced decline phases: $(\mathbf{a}, \mathbf{b})$ are total samples from E. gracilis and M. aeruginosa; $(\mathbf{c}, \mathbf{e}, \mathbf{g})$ are, respectively, HPO, TPH and HPI fractions of AOM produced by E. gracilis and (d,f,h) are, respectively, HPO, TPH and HPI fractions from M. aeruginosa. 


\subsection{Size Fractionation of Organic Matters in Different Stages}

A size fractionation protocol was applied in order to separate organic matter in several fractions according to the apparent molecular weight of molecules. Such a protocol well correlates with the fractionation according to the hydrophobic character and was used here both to evaluate the repartition of the size of organic molecules during the different growth phases of the cultures of E. gracilis and M. aeruginosa and to identify the most abundant ones in the HA, FA, HPO, TPH and HPI fractions from different origins.

Figure $2 \mathrm{a}-\mathrm{h}$ show size fractionation of total samples from cultures, HPO, TPH and HPI fractions during stationary phase (fresh organic material) and advanced decline phase (degraded material). Figure 3a,b show size fractionation of organic material from the Suwannee river and peat (a), as well as that of fractions from the Pigeard pond (b) for comparison.
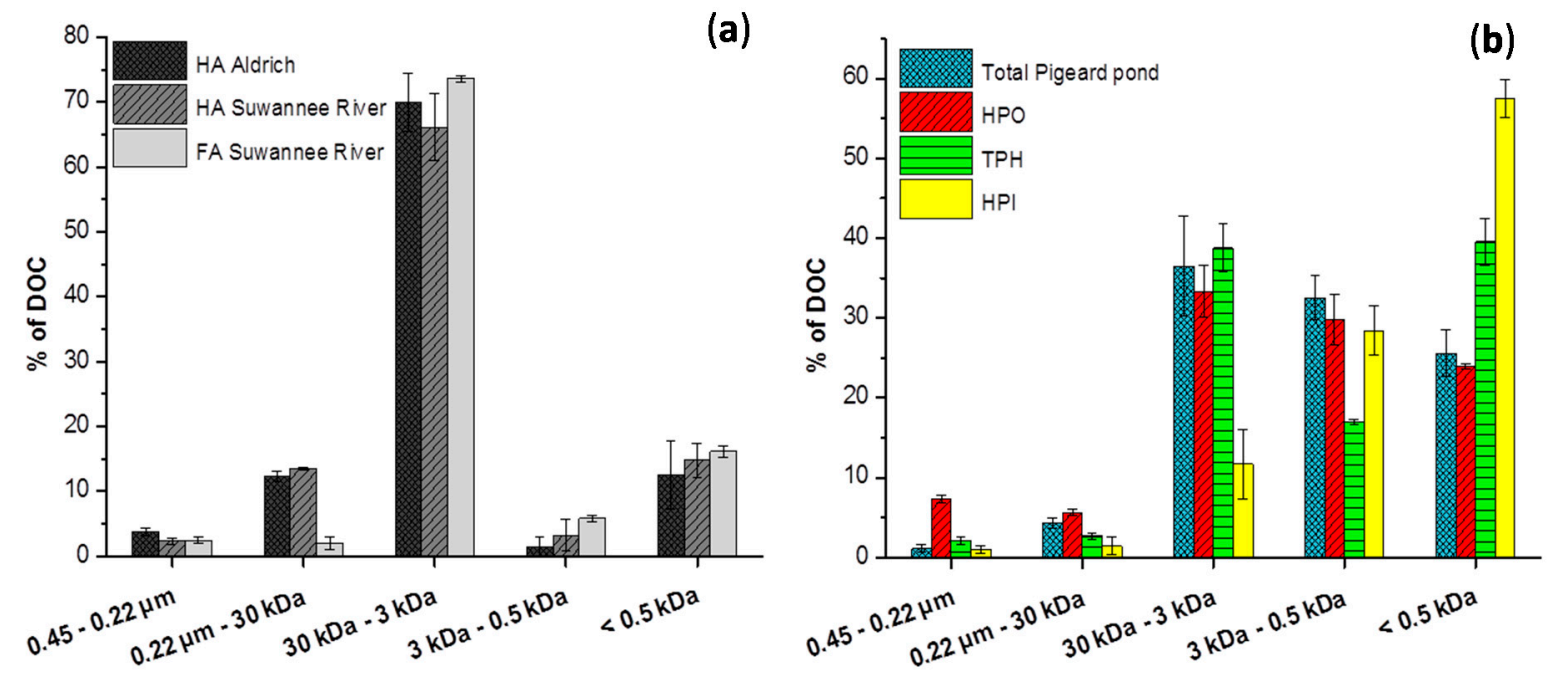

Figure 3. Size fractionation of HA and FA from peat and the Suwannee river are given in (a) and that from Pigeard pond in (b).

Molecular size distribution was dependant on the species and the growth phase but a similar evolution was noticed for both species. Size distribution of AOM was modified and molecular weights tended to increase between the stationary and advanced decline phases. During the stationary phase and whatever the HPO, TPH and HPI fractions, molecules less than $0.5 \mathrm{kDa}$ accounted for the major size fraction of freshly produced AOM. Results of total samples were consistent with those obtained by Henderson et al. [18], who observed that $30 \%-80 \%$ of $\mathrm{AOM}$ is less than $1 \mathrm{kDa}$. Then, after more than one year of evolution, the part of size fraction more than $0.5 \mathrm{kDa}$ increased. This phenomenon can be explained by combination of biopolymers release from cells death as IOM is of larger size than EOM [20] and transformation processes of AOM over a long period. However, the impacts of transformation processes were predominant, as previously explained from the observed HPO increase. Increase in molecular size is, thus, in accordance with consequences of humification-like processes [14] and reflects the advance of transformation of AOM.

Specific evolution pathways were observed for HPO, TPH and HPI fractions but similar tendencies were noticed for both species. For the HPO (Figure 2c,d) and TPH (Figure 2e,f) fractions, the part of 
size fraction between 3 and $0.5 \mathrm{kDa}$ increased while the one less than $0.5 \mathrm{kDa}$ was reduced. On the contrary, part of the size fraction of hydrophilic compounds (Figure 2g,h) comprised between 30 and $3 \mathrm{kDa}$ increased and those of fractions less than $3 \mathrm{kDa}$ decreased. Because HPI remains predominant in AOM, it imposed the evolution of total samples (Figure 2a,b). Labanowski and Feuillade observed in natural waters that the greater the size, the higher the aromaticity [25]. However, during advanced decline phase, HPI fraction had similar content of 3-30 kDa size fraction but lower SUVA index than the HPO fraction. Thus, HPI produced by maturation of AOM contained large and aliphatic structures, while HPO structures were much more aromatic. As regards AOM, some studies provided evidences that the main part of carbohydrates is contained in the HPI fraction $(50 \%-80 \%)$, while $60 \%-65 \%$ of proteins are contained into the HPO fraction $[18,27]$. TPH fraction only contains between $5 \%-15 \%$ of the carbohydrates and proteins according to the authors previously cited. Biochemical composition of HPO and TPH fractions coming from the growth of E. gracilis and M. aeruginosa was analyzed by mass spectrometry.

The results were different during the early stationary phase: proteic markers were relatively more abundant in HPO than in TPH, contrary to the sterols ones [28]. These differences in composition may explain why transformation and stabilization processes were different for each fraction. Humification-like processes involving polymerization of polysaccharides may be predominant for HPI, leading to an increase in the 3-30 $\mathrm{kDa}$ size fraction part and explaining the obtained large and aliphatic structures. For HPO and TPH fractions, transformation processes involving condensation of proteins (more aromatic than polysaccharides) may rather be predominant and lead to an increase in the part of size fraction $0.5-3 \mathrm{kDa}$.

Chemical composition of plants and algae are very different so theories commonly used to explain formation of HS in soils cannot be directly applied to explain AOM transformation. Lignin, tannin and polyphenols humification theories do not apply to AOM because they are minor constituents of algae and microorganisms cells [29]. However, polyphenols theory may apply indirectly. Indeed, this theory could be envisaged after AOM bacterial assimilation because polyphenols can be synthesized from organic carbon sources by micro-organisms [3]. Polyphenols can be degraded into quinones and reactions can occur spontaneously with sugars or amino-acids for example. Because bacteria degrade preferentially labile organic compounds, such as those contained in the HPI and TPH fractions, the first steps of polyphenols theory may explain the evolution of these two fractions, whereas reactions between by-products and other organic compounds may affect each of the three fractions. Cyanobacteria and green algae are known to produce significant levels of terpenes [30], which are stored or released during stationary phase or senescence, depending on the species and the environmental conditions [31]. Thus, terpenes association with proteins and polysaccharides could also be envisaged.

Composition of AOM varies depending on the species, the growth phase and the environmental conditions [32]. Polysaccharides, proteins (30\% to 55\% of dry algal biomass according to López et al. [33]), peptides, amino acids and other organic acids like fatty acids are the main constituents [34]. Condensation and polymerization reactions of fatty acids or poly-unsaturated lipids can also be envisaged. However, Maillard type reactions leading to condensation between polysaccharides and amino-acids are unfavorable or very slow under the used conditions. Indeed, they need to be catalyzed by temperature or, like in soils by manganese or iron oxides according to Jokic et al., and Qi et al. for example $[35,36]$. 

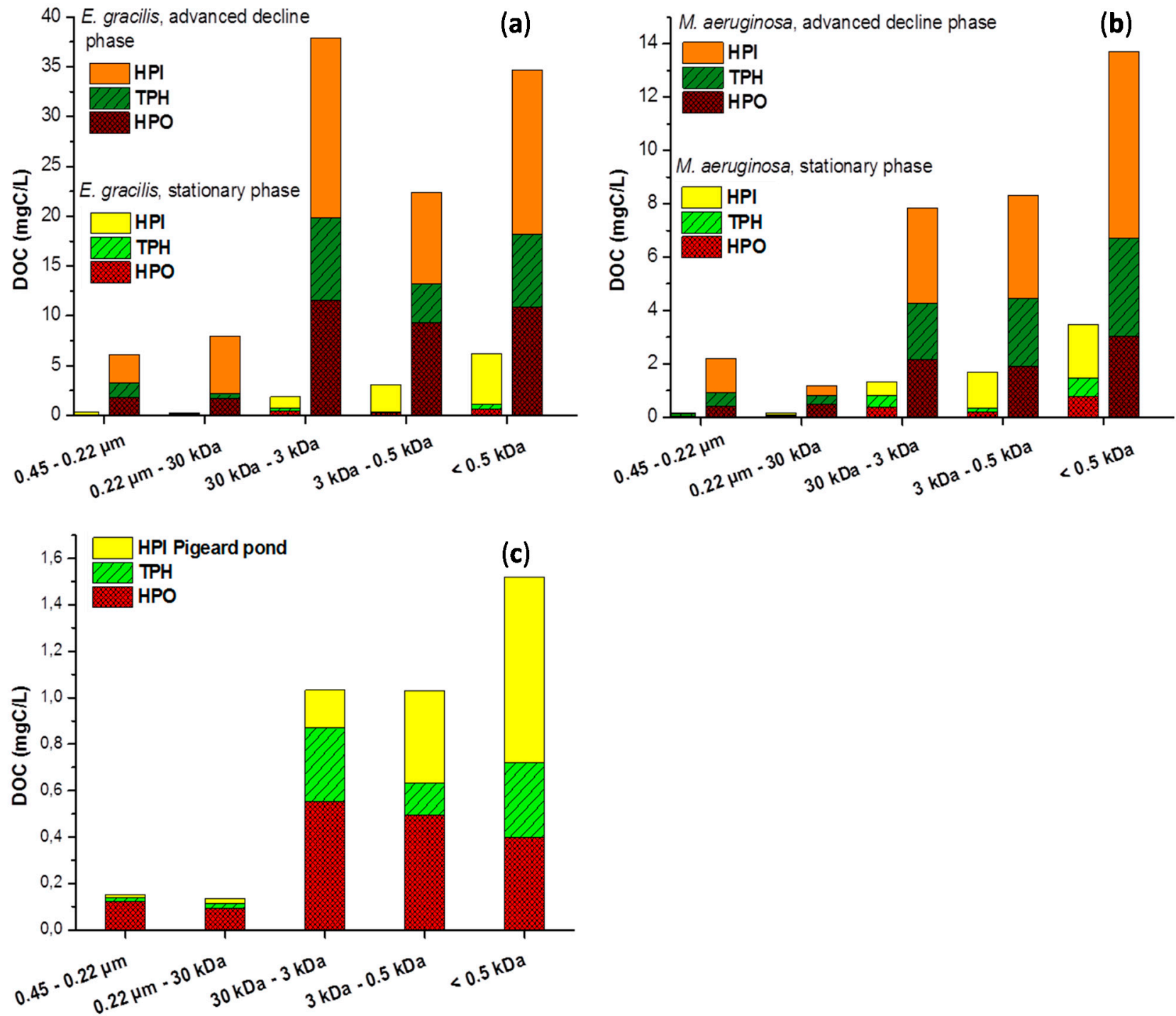

Figure 4. Concentration of HPO, TPH and HPI fractions in the different size fractions during the stationary and advanced decline phases for E. gracilis (a) and M. aeruginosa (b) and during winter for Pigeard pond (c).

Figure $3 a, b$ compare the size fractionation of organic matter derived from soil and surface water resources and show that size fraction between 30 and $3 \mathrm{kDa}$ was largely predominant $(>65 \%)$ in $\mathrm{HA}$ and FA. High content in organic molecules of high molecular weight correlates with an advanced degree of humification [14]. Thus, humification processes of allochthonous organic material mainly led to the formation of 3-30 $\mathrm{kDa}$ compounds. Some consequences of eutrophication and AOM humification-like processes can be anticipated for natural organic matter from surface water resources. HPO and FA fractions are experimentally similar, also when comparing FA from the Suwannee River and HPO extracted from phytoplankton during the advanced decline phase, 3-30 kDa content was significantly lower for the latter. This difference can be explained either by the presence of different precursors leading to the formation of different HS or by requirement of a very long time to achieve a second stage of evolution for AOM, during which 3-30 kDa part of the HPO would increase. Nevertheless, both assumptions result in a low content of size fraction 3-30 kDa for HPO from the eutrophic Pigeard pond (Figure 3a), compared to the river not affected by blooms (37\% vs. 75\%). 
This gap is expected to widen in the long term because of annual AOM inputs and consequences of its humification-like processes. Then, another impact of eutrophication is the recurrent input of freshly produced HPI by phytoplankton. Although sampling was performed during winter, when phytoplanktonic activity was weak, the size profile of the HPI fraction from Pigeard pond was similar to those of fresh $\mathrm{AOM}$, in which fractions lower than $3 \mathrm{kDa}$ were the most abundant and especially the size fraction less than $0.5 \mathrm{kDa}$. This phenomenon cannot result from an artifact of the fractionation procedure because the HPI size profile was significantly modified during the advanced decline phase, especially for E. gracilis. It rather seems to indicate that the degree of transformation of HPI remains low in Pigeard pond. Because HPI content is expected to increase in eutrophic water resources in the long term, contribution of hydrophilic compounds in each size fraction (Figure 4) is expected to increase in the affected water resources. The extent of the consequences of eutrophication on the characteristics of NOM is likely to depend on the humification-like processes of AOM.

\section{Experimental Section}

AOM was extracted from mono-specific cultures of algae and cyanobacteria. Characteristics of AOM were compared with those of organic matter extracted during winter from a shallow artificial and eutrophic pond located in the Limousin area (latitude $45^{\circ} 54^{\prime} \mathrm{N}$ and longitude $1^{\circ} 11^{\prime} \mathrm{E}$, Nieul, France), the Pigeard pond. This pond is well known for its high algal productivity. A characterization of organic matter fractions coming from Pigeard pond, HA provided by Aldrich (Saint-Louis, MO, USA) and HA $(2 \mathrm{~S} 101 \mathrm{H})$ and FA $(2 \mathrm{~S} 101 \mathrm{~F})$ extracted from the Suwannee River and provided by the International Humic Substances Society (IHSS, Denver, CO, USA), was performed for comparison.

\subsection{Samples Preparation}

\subsubsection{Algae and Cyanobacteria Cultivation}

Non axenic strains of E. gracilis and M. aeruginosa provided by the National Museum of Natural History (Paris, France), were used to stand for microbial activity happening in natural waters. The two species were grown in $1 \mathrm{~L}$ Erlenmeyer flasks filled up with $500 \mathrm{~mL}$ of synthetic sterilized Chu 10 modified medium, according to the protocol used by Leloup et al. [21]. Cultures were grown at

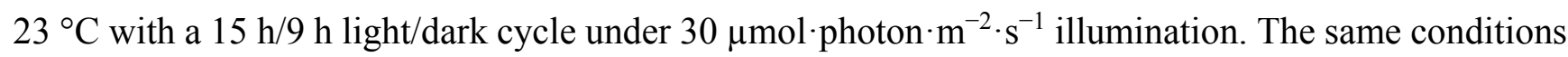
were maintained until the end of experiment. Progressive evaporation occurring during the experiment was taken into account by application of a correcting factor for calculations, depending on the measured final volume on initial volume ratio.

\subsubsection{Organic Matter Extraction Procedure}

AOM was extracted from cultures during the stationary growth phase (21 and 28 days for E. gracilis and $M$. aeruginosa, Figure 1) and the advanced decline phase, after one year and four months of cultivation. The duration of the experiment (more than a year) was chosen to reflect the transformation of AOM over a long period of time after its production and because fresh AOM inputs occur on an annually basis in eutrophic water resources. Both AOM and NOM from Pigeard pond were extracted according to the Malcolm and MacCarthy's protocol [37], by adsorption on DAX-8 and XAD-4 resins 
in series. The fractionation protocol allowed separating organic matter into four fractions: HA, HPO, TPH and HPI fractions. However as HA were not produced in sufficient quantity for analyses $(<3 \%$ of DOC), only three fractions were characterized in this work. The partition coefficient $k^{\prime}$ was fixed to 50.

Cultures were first centrifuged at $6000 \times g$ during 20 min at $4{ }^{\circ} \mathrm{C}$. Natural samples and centrifuged culture medium were both filtered on $0.45 \mu \mathrm{m}$ cellulose nitrate membrane and HA were removed by samples acidification at $\mathrm{pH} 2$ with $\mathrm{HCl} 37 \%$ and filtration on $0.45 \mu \mathrm{m}$. HPO were retained on DAX-8 resin; TPH were retained on XAD-4 resin and HPI were not retained on resins and remained in the sample with salts. Before desorption, resins were rinsed with formic acid at $\mathrm{pH} 2$. HPO and TPH fractions were desorbed with Acetonitrile 75\%/Water 25\% $(v / v)$. Organic matter recovery is almost $100 \%$ by using such mixture as the eluent [38]. Acetonitrile was finally removed by evaporation and both fractions were freeze-dried.

\subsection{Organic Matter Characterization}

\subsubsection{Size Fractionation}

$\mathrm{pH}$ of each sample was adjusted to 6.5 prior to size fractionation, which was performed by ultrafiltration using a diafiltration method. This method consists in keeping the volume of sample constant in the ultrafiltration cell by adding a sodium nitrate solution with the same ionic strength as the sample. It allows reducing measurements disturbance due to polarization of concentration phenomenon. The detailed protocol is described elsewhere [25]. Ionic strength was calculated from the electrical conductivity of the sample (measured with a WTW LF 538 conductimeter of precision $\pm 0.5 \%$ ) by using the Marion-Babcock Equation (Equation (1)) [39].

$$
\begin{gathered}
\log I=1.159+1.009 \log \chi ; \\
I \text { ionic strength in } \mathrm{mmol} \cdot \mathrm{L}^{-1} \text { and } \chi \operatorname{conductivity~in~} \mathrm{mS} \cdot \mathrm{cm}^{-1}
\end{gathered}
$$

Organic molecules were separated into five fractions (four fractions comprised between: 0.45 and $0.2 \mu \mathrm{m}, 0.2 \mu \mathrm{m}$ and $30 \mathrm{kDa}, 30$ and $3 \mathrm{kDa}, 3$ and $0.5 \mathrm{kDa}$, and one fraction less than $0.5 \mathrm{kDa}$ ) by successive filtration of sample through 0.45 and $0.2 \mu \mathrm{m}$ cellulose nitrate membranes, YM Amicon membrane of 30 and $3 \mathrm{kDa}$, as well as YC Amicon membrane of $0.5 \mathrm{kDa}$ molecular weight cut-offs. The samples filtration was carried out under 3 bars pressure of compressed air. The proportion of each fraction was determined by measuring DOC content of the filtrates and the retentates. Analyses were performed in duplicates.

\subsubsection{Dissolved Organic Carbon Measurements}

DOC measurements were performed by a Shimadzu TOC-L analyzer (precision $\pm 2 \%$, Shimadzu, Kyoto, Japan) according to the Non-Purgeable Organic Carbon measurement procedure.

\subsubsection{Specific UV Absorbance Index}

The SUVA index is defined as the ratio of the UV absorbance at $254 \mathrm{~nm}$ to the DOC concentration. The UV absorbance at $254 \mathrm{~nm}$ was measured by using a Shimadzu PharmaSpec 1700 spectrophotometer (precision $\pm 0.005 \mathrm{~cm}^{-1}$; Shimadzu, Kyoto, Japan) with $1 \mathrm{~cm}$-long quartz cells. This index allows 
estimating the aromaticity of each fraction and correlates with the hydrophobicity of organic molecules [26,38]. Analyses were performed in duplicate.

\section{Conclusions}

The evolution of AOM properties in the long term predominantly resulted from humification-like processes than from a single process of biopolymer release from cells decay. Compounds formed by AOM transformation were either different from HS generated by humification because the precursors were different or required a very long time to allow their properties to become closer. Each organic fraction (HPO, TPH and HPI) evolved differently from the others, depending on its composition, but these processes were similar for both the algae and the cyanobacteria. A faster evolution of M. aeruginosa's AOM compared to that of E. gracilis was probably due to a shorter stationary phase, which allowed degradation and transformation processes from biotic and abiotic factors to occur earlier. E. gracilis population declined slowly, likely because of mixotrophy. The extent of the consequences of eutrophication on the NOM characteristics of natural water resources is likely to depend on the impacts of humification-like processes of AOM: increase in HPI content whose properties would remain close to freshly produced HPI fraction of phytoplanktonic origin associated to a decrease in molecular weights of HPO compounds. Further in situ studies would be required to confirm these assumptions.

\section{Acknowledgments}

The authors thank the FEDER (European Found for Regional Development) and the Regional Council of Limousin for their financial support.

\section{Author Contributions}

Maud Leloup designed the experiments with Geneviève Feuillade-Cathalifaud, performed the experiments, interpreted the results with all co-authors and wrote the article; Virginie Pallier and Rudy Nicolau participated to the data interpretation and corrected the manuscript; Geneviève Feuillade-Cathalifaud supervised the research project, participated to the data analysis and article writing.

\section{Conflicts of Interest}

The authors declare no conflicts of interest.

\section{References}

1. Thurman, E.M. Organic Geochemistry of Natural Waters; Springer Science \& Business: Dordrecht, The Netherlands, 1985.

2. Semenov, V.M.; Tulina, A.S.; Semenova, N.A.; Ivannikova, L.A. Humification and nonhumification pathways of the organic matter stabilization in soil: A review. Eurasian Soil Sci. 2013, 46, 355-368.

3. Stevenson, F.J. Humus Chemistry: Genesis, Composition, Reactions; John Wiley \& Sons: New York, NY, USA, 1982. 
4. Wershaw, R.L. Evaluation of Conceptual Models of Natural Organic Matter (Humus) from a Consideration of the Chemical and Biochemical Processes of Humification; Scientific Investigations Report 2004-5121: Denver, CO, USA, 2004.

5. Stevenson, F.J. Humus Chemistry: Genesis, Composition, Reactions, 2nd ed.; John Wiley \& Sons: New York, NY, USA, 1994.

6. Cheshire, M.V.; Russell, J.D.; Fraser, A.R.; Bracewell, J.M.; Robertsons, G.W.; Benzing-Purdie, L.M.; Ratcliffe, C.I.; Ripmeester, J.A.; Goodman, B.A. Nature of soil carbohydrate and its association with soil humic substances. J. Soil Sci. 1992, 43, 359-373.

7. Zech, W.; Ziegler, F.; Kogel-Knabner, I.; Haumaier, L. Humic substances distribution and transformation in forest soils. Sci. Total Environ. 1992, 117-118, 155-174.

8. Piccolo, A. The supramolecular structure of humic substances. Soil Sci. 2001, 166, 810-832.

9. Sutton, R.; Sposito, G. Molecular structure in soil humic substances: The new view. Environ. Sci. Technol. 2005, 39, 9009-9015.

10. Chin, Y.-P.; Aiken, G.; O’Loughlin, E. Molecular weight, polydispersity, and spectroscopic properties of aquatic humic substances. Environ. Sci. Technol. 1994, 28, 1853-1858.

11. Peuravuori, J.; Pihlaja, K. Molecular size distribution and spectroscopic properties of aquatic humic substances. Anal. Chim. Acta 1997, 337, 133-149.

12. Perminova, I.V.; Frimmel, F.H.; Kudryavtsev, A.V.; Kulikova, N.A.; Abbt-Braun, G.; Hesse, S.; Petrosyan, V.S. Molecular weight characteristics of humic substances from different environments as determined by size exclusion chromatography and their statistical evaluation. Environ. Sci. Technol. 2003, 37, 2477-2485.

13. Zech, W.; Haumaier, L.; Kögel-Knabner, I. Changes in aromaticity and carbon distribution of soil organic matter due to pedogenesis. Sci. Total Environ. 1989, 81-82, 179-186.

14. Merritt, K.A.; Erich, M.S. Influence of organic matter decomposition on soluble carbon and its copper-binding capacity. J. Environ. Qual. 2003, 32, 2122.

15. McKnight, D.M.; Boyer, E.W.; Westerhoff, P.K.; Doran, P.T.; Kulbe, T.; Andersen, D.T. Spectrofluorometric characterization of dissolved organic matter for indication of precursor organic material and aromaticity. Limnol. Oceanogr. 2001, 46, 38-48.

16. Wang, L.; Wu, F.; Zhang, R.; Li, W.; Liao, H. Characterization of dissolved organic matter fractions from Lake Hongfeng, Southwestern China Plateau. J. Environ. Sci. 2009, 21, 581-588.

17. Her, N.; Amy, G.; Park, H.-R.; Song, M. Characterizing algogenic organic matter (AOM) and evaluating associated NF membrane fouling. Water Res. 2004, 38, 1427-1438.

18. Henderson, R.K.; Baker, A.; Parsons, S.A.; Jefferson, B. Characterisation of algogenic organic matter extracted from cyanobacteria, green algae and diatoms. Water Res. 2008, 42, 3435-3445.

19. Zhang, Y.; Tian, J.; Nan, J.; Gao, S.; Liang, H.; Wang, M.; Li, G. Effect of PAC addition on immersed ultrafiltration for the treatment of algal-rich water. J. Hazard. Mater. 2011, 186, 1415-1424.

20. Li, L.; Gao, N.; Deng, Y.; Yao, J.; Zhang, K. Characterization of intracellular \& extracellular algae organic matters (AOM) of Microcystic aeruginosa and formation of AOM-associated disinfection byproducts and odor \& taste compounds. Water Res. 2012, 46, 1233-1240. 
21. Leloup, M.; Nicolau, R.; Pallier, V.; Yéprémian, C.; Feuillade-Cathalifaud, G. Organic matter produced by algae and cyanobacteria: Quantitative and qualitative characterization. J. Environ. Sci. 2013, 25, 1089-1097.

22. Kassim, G.; Martin, J.P.; Haider, K. Incorporation of a wide variety of organic substrate carbons into soil biomass as estimated by the fumigation procedure. Soil Sci. Soc. Am. J. 1981, 45, 1106-1112.

23. Pivokonsky, M.; Safarikova, J.; Baresova, M.; Pivokonska, L.; Kopecka, I. A comparison of the character of algal extracellular versus cellular organic matter produced by cyanobacterium, diatom and green alga. Water Res. 2014, 51, 37-46.

24. Fang, J.; Yang, X.; Ma, J.; Shang, C.; Zhao, Q. Characterization of algal organic matter and formation of DBPs from chlor(am)ination. Water Res. 2010, 44, 5897-5906.

25. Labanowski, J.; Feuillade, G. Combination of biodegradable organic matter quantification and XAD-fractionation as effective working parameter for the study of biodegradability in environmental and anthropic samples. Chemosphere 2009, 74, 605-611.

26. Weishaar, J.L.; Aiken, G.R.; Bergamaschi, B.A.; Fram, M.S.; Fujii, R.; Mopper, K. Evaluation of specific ultraviolet absorbance as an indicator of the chemical composition and reactivity of dissolved organic carbon. Environ. Sci. Technol. 2003, 37, 4702-4708.

27. Qu, F.; Liang, H.; He, J.; Ma, J.; Wang, Z.; Yu, H.; Li, G. Characterization of dissolved extracellular organic matter (dEOM) and bound extracellular organic matter (bEOM) of Microcystis aeruginosa and their impacts on UF membrane fouling. Water Res. 2012, 46, 2881-2890.

28. Nicolau, R.; Leloup, M.; Lachassagne, D.; Pinault, E.; Feuillade-Cathalifaud, G. Matrix-assisted laser desorption/ionization time-of-flight mass spectrometry (MALDI-TOF-MS) coupled to XAD fractionation: Method to algal organic matter characterization. Talanta 2015, 136, 102-107.

29. Higuchi, T. Lignin biochemistry: Biosynthesis and biodegradation. Wood Sci. Technol. 1990, 24, $23-63$.

30. Juttner, F. Physiology and biochemistry of odorous compounds from freshwater cyanobacteria and algae. Water Sci. Technol. 1995, 31, 69-78.

31. American Water Works Association. M57-Algae: Source to Treatment; American Water Works Association: Denver, CO, USA, 2010.

32. Pivokonsky, M.; Kloucek, O.; Pivokonska, L. Evaluation of the production, composition and aluminum and iron complexation of algogenic organic matter. Water Res. 2006, 40, 3045-3052.

33. López, C.V.G.; García, M.D.C.C.; Fernández, F.G.A.; Bustos, C.S.; Chisti, Y.; Sevilla, J.M.F. Protein measurements of microalgal and cyanobacterial biomass. Bioresour. Technol. 2010, 101, 7587-7591.

34. Cardozo, K.H.M.; Guaratini, T.; Barros, M.P.; Falcão, V.R.; Tonon, A.P.; Lopes, N.P.; Campos, S.; Torres, M.A.; Souza, A.O.; Colepicolo, P.; et al. Metabolites from algae with economical impact. Comp. Biochem. Physiol. Part C Toxicol. Pharmacol. 2007, 146, 60-78.

35. Jokic, A.; Frenkel, A.I.; Vairavamurthy, M.A.; Huang, P.M. Birnessite catalysis of the maillard reaction: Its significance in natural humification. Geophys. Res. Lett. 2001, 28, 3899-3902.

36. Qi, G.; Yue, D.; Fukushima, M.; Fukuchi, S.; Nishimoto, R.; Nie, Y. Enhanced humification by carbonated basic oxygen furnace steel slag-II. Process characterization and the role of inorganic components in the formation of humic-like substances. Bioresour. Technol. 2012, 114, 637-643. 
37. Malcolm, R.L.; MacCarthy, P. Quantitative evaluation of XAD-8 and XAD-4 resins used in tandem for removing organic solutes from water. Environ. Int. 1992, 18, 597-607.

38. Croué, J.-P. Isolation of humic and non-humic NOM fractions: Structural characterizations. Environ. Monit. Assess. 2004, 92, 193-207.

39. Sposito, G. The Chemistry of Solids; Oxford Univerity Press: New York, NY, USA, 1989.

(C) 2015 by the authors; licensee MDPI, Basel, Switzerland. This article is an open access article distributed under the terms and conditions of the Creative Commons Attribution license (http://creativecommons.org/licenses/by/4.0/). 